\title{
DIALÉTICA E POLÍTICA EM HEGEL
}

Thadeu'Weber*

SÍNTESE - A dialética hegeliana não pode ser entendida apenas como método ou instrumento de pensar, mas também como conteúdo pensado. A política é o desdobramento ou concretização do principio da liberdade enquanto fio condutor e organizador das estruturas jurídicas e sociais, dentro de um processo dialético.
ABSTRACT - Hegel's dialectic cannot be understood unly as a method or instrument of thinking but also as a thought content. Politics is the unfoldment or concretization of the principle of freedon as a connecting thread, organizing the legal and social structures, within a dialectical process.

\section{1 - 0 que é dialética?}

Hegel, na Fenomenologia do Espírito, escreve: "O botão desaparece no desabrochar da flor, e pode-se dizer que é refutado pela flor. Igualmente, a flor se explica por meio do fruto como um falso existir da planta, e o fruto surge em lugar da flor como verdade da planta" (Phänomenologie des Geistes - PhG. - p. 12).

Esta figura, exemplar, explica a estrutura triádica da dialética, embora um sistema filosófico não possa ser reduzido a uma única tríade que se repete, sempre. Botão, flor e fruta são momentos que constituem a unidade orgânica de uma planta, ou seja, cada momento existe em função do outro e, juntos, formam a vida do todo. O botão, negado na flor, e ambos, botão e flor, superados e conservados, estão no fruto. $\mathrm{O}$ fruto, resultado de um processo de negação, conservação e superação dos momentos anteriores, surge como a verdade da planta. A verdade, portanto, não está num desses momentos (botão ou flor), mas no todo, a rigor, está no fruto, e este tão somente é se os outros momentos também são. É importante observar que o movimento dialético no caso da planta é sempre o mesmo (botão, flor, fruto), isto é, pára na primeira tríade. Não é o que acontece no sistema filosófico, onde sempre novas sinteses, e portanto novas teses, surgirão, trazendo os momentos anteriores como superados e guardados.

O funcionamento da estrutura da dialética pode ser mais claramente explicitado em seu movimento progressivo com uma breve análise do primeiro capítulo da Fenomenologia do Espírito: "A certeza sensivel". Esta obra propõe-se mostrar a evolução da consciência ingênua, isto é, do saber imediato, até o saber absoluto. Os momentos desse movimento constituem a mais clara apresentação do desdo-

* Pontificia Universidade Católica, PUCRS.

\begin{tabular}{|l|l|l|l|l|l|}
\hline VERTTAS & Porto Alegre & v. 40 & $\mathrm{n}^{\circ} 160$ & Dezembro 1995 & p. 759-768 \\
\hline
\end{tabular}


bramento do processo dialético hegeliano que, enquanto estrutura, se repete em todo o sistema.

A certeza sensivel (primeira figura da consciência) aparece, enquanto saber imediato, ao mesmo tempo como a mais verdadeira e a mais abstrata e mais pobre. Mais verdadeira, porque mantém o objeto ou o isto na sua totalidade; mais pobre, porque nada diz sobre ele. Só diz que ele é. $O$ ponto de partida da relação dialética entre sujeito e objeto de conhecimento é, portanto, um puro eu e um puro isto. Mas se observarmos bem esta relação, veremos que, numa "certeza sensível efetiva", o eu e o isto já estão mediatizados. O eu só é em função do isto e o isto só é tal em vista do eu. Ou seja, um momento só é em função do outro.

Impõe-se a pergunta: Na certeza sensivel, qual dos momentos, sujeito ou objeto, é o essencial nesta relação? O eu que sabe parece que só pode saber se o objeto é. Mas o saber pode ser ou não ser. O objeto, no entanto, é, independentemente do fato de ser objeto do saber ou não. Parece, então, que o objeto é o essencial na certeza sensivel, uma vez que o saber não é se o objeto não é (cf. PhG. p. 83). Precisamos, portanto, submeter o objeto à análise para ver se ele é, de fato, o essencial na certeza sensível. Interroguemos o isto, escreve Hegel, no duplo aspecto de seu ser, ou seja, como agora e como aqui. O que é o agora? Digamos que o agora seja dia e anotemos por escrito esta verdade. Olhemos para a verdade anotada quando o agora não é mais dia e sim noite, e verificaremos que aquela verdade, aquele caráter de certeza ingênua que tinha inicialmente, ficou sem sentido, isto é, falsa. Qual é, então, a verdade do agora, o dia ou a noite? Nenhum e os dois ao mesmo tempo, no agora universal. O dia foi mediado, portanto, negado pela noite, e ambos, o dia e a noite, estão conservados no nível universal (síntese). 0 agora conservado não é mais um agora imediato, mas mediatizado por outro agora que é a noite. A verdade não está em nenhum deles, mas em ambos enquanto superados e guardados num nivel superior. O mesmo ocorre com o aqui. Se eu disser que o aqui é, por exemplo, uma árvore e me viro e vejo que o aqui não é mais a árvore e sim uma casa, observo que o aqui imediato como árvore desapareceu, isto é, ao ser negado e mediado pela casa, reaparece no aqui universal, que supera e guarda ambos os aquis.

É importante observar que o agora (dia, noite) e o aqui (árvore, casa) singulares, enquanto objetos do nosso opinar, são conservados porque eu os mantenho (cf. PhG. p. 84). O dia e a noite não desaparecem porque eu os conservo. Ora,isto significa que aquilo que parecia ser o essencial da certeza sensível - o objeto - tornou-se o inessencial. Agora o essencial parece ser o eu, exatamente porque conserva o universal que permanece em meio ao desaparecimento do aqui e agora imediatos. A falsidade da tese e da antítese nos reporta à síntese que nega, conserva e supera os momentos anteriores.

A mesma experiência feita com o objeto pode ser feita com o eu. Igualmente pode-se mostrar que nem ele é o essencial da certeza sensivel. Um eu diz árvore, outro eu diz mesa. Ambas' as verdades têm o mesmo grau de credibilidade. Uma, no entanto, desaparece na outra. O que não desaparece é o eu como universal. Isto mostra que o eu individual já é sempre um eu universal. Assim, o eu e o objeto são momentos do todo que é o verdadeiro da certeza sensível. 
Na dialética do eu e do objeto fica, assim, demonstrado que a essência da certeza sensivel não está num momento enquanto imediato e, sim, no todo, ou seja, na mediação dos momentos singulares, que leva a um universal.

É importante insistir no caráter de provisoriedade de toda síntese, neste movimento triádico da dialética. Isto significa que sempre novas sínteses se impõem. Em cada síntese os momentos anteriores, tese e antítese (também provisórios enquanto imediatos), estão negados mas, ao mesmo tempo, integrados numa síntese superior. Tomemos outro exemplo: Tese: Tudo é absoluto; Antítese: Tudo é relativo; Síntese: Pelo menos é absoluto que tudo é relativo. À tese ou afirmação imediata, é contraposta uma proposição contrária - a antítese. A afirmação, dada sua falsidade ou parcialidade, nos leva à negação, também falsa ou insuficiente. Da falsidade de ambas resulta uma síntese ou negação da negação, verdadeira. Outro exemplo: Tomemos como tese o sistema capitalista. A ele foi historicamente contraposto o comunismo; ou seja, este nega os princípios fundamentais do capitalismo. Ambos os sistemas são contrários, isto é, ambos podem ser simultaneamente falsos. Se colocarmos o socialismo como síntese ou negação da negação, temos que mostrar como este nega, supera e conserva momentos ou princípios do capitalismo e do comunismo na tentativa de conciliá-los. Para ser síntese, o socialismo deve superar e guardar a tese e a antítese em iguais proporções para poder conciliá-los num nivel superior. Se agora se perguntar pela possibilidade efetiva dessa conciliação, isto já se constitui num outro problema. Pois, se não houver esta possibilidade em nenhum dos seus princípios, já não se pode falar em dialética. E mesmo assim cabe a pergunta: o que fica de fora desta conciliação?

Pelo que se pode observar, a negação da negação engloba, ao mesmo tempo, a afirmação e a negação, revelando o verdadeiro valor de ambas numa forma superior (cf. Weber, 1993, p. 42). Isto indica que na negação da negação, a afirmação e a negação estão negadas, superadas e guardadas e não simplesmente somadas. Escreve Hegel na Fenomenologia da Espirito: "A riqueza do existir anterior está presente na recordação" (p. 16). A síntese final, se houver, deverá conter todos os momentos anteriores como superados e conservados. "O verdadeiro é o todo. Mas o todo é somente a essência que atinge a completude por meio de seu desenvolvimento" (PhG. p. 24). Na Filosofia do Direito, lemos: "O princípio motor do conceito - enquanto não é simplesmente análise mas também produção das particularidades do universal - é o que eu chamo de dialética" (Rechtsphilosophie - Rph. - \& 31). Daí a necessidade de se mostrar, na perspectiva hegeliana, o desdobramento do sistema para explicitar sua concepção de dialética.

Estas considerações nos reportam ao texto de C. R. Cirne Lima, "Dialética e Evolução", ${ }^{1}$ na tentativa de explicitar alguns aspectos e mostrar alguns desdobramentos.

A questão básica levantada pelo autor, a propósito da estrutura da dialética, diz respeito à possibilidade e à necessidade de alternativas dentro do processo dialético. Isto requer que a proposição antitética esteja em oposição contrária à proposição tética e não em oposição contraditória (cf. p. 709). Se a oposição fosse entre proposições contraditórias, não haveria alternativas e o sistema ficaria fechado.

1 Nota do editor: $\mathrm{O}$ autor se refere ao primeiro artigo deste número, p. 701. 
Aliás, há uma ambigüidade, que precisaria ser explicitada, no texto de Cirne Lima quando na p. 709 afirma que "proposições contrárias podem ser construídas a priori de maneira totalmente lógica" e na p. 712 afirma que "as antíteses não são dadas (ou construídas) a priori e de forma necessária e sim a posteriori e de forma contingente". Afinal, as proposições contrárias podem ou não ser construídas de forma a priori? No conjunto de sua argumentação, o autor quer demonstrar que a dialética, a rigor, só é possível do ponto de vista lógico, entre proposições contrárias que permitem alternativas contingentes. Logo, não podem ser construídas a priori. Somente de duas proposições contrárias pode surgir uma síntese, uma vez que estas podem ser simultaneamente falsas. De duas proposições contraditórias isto não é possivel, uma vez que não podem ser simultaneamente falsas. Se uma é verdadeira a outra é falsa. Portanto, somente as proposições contraditórias podem ser construídas de forma a priori e não as proposições contrárias.

Se nos referimos ao sistema hegeliano, uma pergunta se impõe: Existem nele alternativas e, portanto, contingência? Cirne Lima, ao se referir a Platão, Cusano e Hegel, admite que "os dialéticos utilizam na elaboração de antíteses quase sempre um conceito novo que eles tiram do grande cesto onde se encontram todas as pressuposições que foram feitas no início" (p. 709). O novo aqui referido implica alternativas contingentes. Significa dizer que na estrutura da dialética, apresentada por Cirne Lima, não é possivel "uma listagem completa e exaustiva de todas as antíteses e de todas as sínteses", uma vez que estas "não são dadas a priori e de forma necessária e sim a posteriori e de forma contingente" (p. 712).

Penso que em Hegel nem sempre é assim. Há alguns momentos antitéticos necessários e outros contingentes. É preciso saber distinguir o que é momento necessário e o que é momento contingente e como se relacionam entre si. A explicação do que seja dialética em Hegel deve passar por esta distinção. Pretendo mostrar isto em algumas figuras da Filosofia do Direito, discutindo, sobretudo, o conceito de mediação política. Acato, assim, a sugestão de Cirne Lima quando indica, na terceira parte de seu texto (Espírito), que "um projeto de Filosofia do Espírito" deveria traçar um esboço entre outros, de uma Filosofia do Direito e de uma Filosofia da História. Ao insistir na possibilidade e necessidade de alternativas dentro da estrutura da dialética, o autor forneceu os instrumentos conceituais para a interpretação ou leitura do sistema hegeliano como um sistema aberto. A segunda parte deste trabalho pretende mostrar isto na Filosofia do Direito de Hegel.

\section{2-Dialética e política}

A filosofia política de Hegel pode ser tomada como uma aplicação e concretização do movimento dialético apresentado na Fenomenologia do Espírito e na Ciência da Lógica. Método e conteúdo, portanto, se confundem. O desdobramento do conteúdo (como será mostrado na Filosofia do Direito) é uma explicitação do método. Esta segunda parte pretende fazer a passagem da estrutura da dialética para o seu desdobramento na filosofia política.

Dialética não é só método ou instrumento de pensar, mas conteúdo pensado. Falar, portanto, da dialética hegeliana implica falar também do sistema ou das figuras do sistema enquanto suas determinações. Falar do método dialético significa 
mostrar como um determinado conteúdo se desdobra (dialeticamente). Escreve Hegel: "A mais elevada dialética do conceito consiste em não considerar a determinação meramente como limite e oposto, mas em produzir a partir dela o conteúdo positivo e o resultado, único procedimento mediante o qual a dialética é desenvolvimento e progresso imanente. Não é, portanto, a ação exterior de um pensar subjetivo, mas a alma própria do conteúdo que faz crescer organicamente seus ramos e seus frutos" (Rph. \& 31). Reporto-me aqui tão somente a uma parte do sistema a Filosofia do Direito - cujo princípio organizador é a Idéia da liberdade. Ela (a Filosofia do Direito) trata da concretização ou desdobramento deste princípio (conteúdo) e o faz de forma dialética.

A liberdade já é apresentada por Hegel, na Ciência da Lógica, como categoria mais nobre. Implica, no entanto, desenvolvimento ou desdobramento. Portanto, a liberdade como princípio orientador e a forma de argumentação (método) devem ser considerados conjuntamente.

Se Hegel, na Filosofia do Direito, pretende expor as estruturas concretas do Direito, tomando por base um princípio de organização, que representa o fio condutor da reconstrução, é no Direito Abstrato que vai apresentar as formas concretas e mais imediatas da realização da Idéia da liberdade. São formas ainda indeterminadas exatamente por não haver mediação social.

A primeira forma mediante a qual a pessoa se dirige ao mundo é através da posse. Esta, no entanto, só lhe dá o direito de uso. Ou seja, a instituição da propriedade privada exige o reconhecimento formal da vontade de outra pessoa para que se constitua o direito de troca. Este reconhecimento se dá pelo contrato - momento antitético do Direito Abstrato. Pelo contrato, por ser uma mediação de vontades livres, dá-se a negação das vontades imediatas, na medida em que um reconhece a vontade do outro. Só assim é possível o momento sintético - a noção do justo ou injusto. Só de duas vontades livres podem surgir atos injustos.

$\mathrm{O}$ que é necessário e o que é contingente nesta tríade dialética - propriedade, contrato, injustiça? Em primeiro lugar, a posse é necessária enquanto concretização da vontade livre, mas a quantidade da posse é contingente. O contrato, que implica no livre consentimento das vontades envolvidas, é condição necessária como critério de injustiça, pois, ferir o pacto é injusto. A síntese, portanto, é conseqüência lógica da antítese (contrato). Mas o tipo de síntese depende do tipo de contrato. Para saber se determinado ato é justo ou injusto temos que verificar o que reza o contrato. O contrato, no entanto, é contingente do ponto de vista de seu conteúdo, isto é, constituído por vontades contingentes, não podem ser determinados a priori os termos que o constituem. Exatamente por ser celebrado por vontades contingentes, e na maioria das vezes sobre matéria contingente, é que pode ser desfeito ou mudado. Há, portanto, várias antíteses (alternativas) possiveis para uma mesma tese e, por conseguinte, várias sinteses.

Não pretendo entrar no tema da moralidade e sim no da eticidade hegeliana a fim de mostrar como se dá a mediação social da liberdade, ou seja, como o "eu" torna-se "nós" através do processo dialético de mediação das vontades, dentro das instituições sociais. Pretendo mostrar, em última análise, como o eu individual torna-se família, sociedade civil, Estado. Afirma Cirne Lima, e isto já está em Hegel: O eu individual já é desde sempre um eu universal (cf. "Dialética e Evolução", p. 
722). A Fenomenologia do Espírito é uma clara demonstração desta tese. A mesma experiência pode ser feita do ponto de vista político.

A eticidade trata da mediação social da liberdade, isto é, das relações objetivas; da dimensão supra-individual. Ao definir a eticidade, na Filosofia do Direito, Hegel escreve: "Que minha vontade seja posta como adequada ao conceito e com isso superada e guardada (aufgehoben) sua subjetividade" (\& 142). A vontade imediata do eu individual, e como tal contingente, exige objetivação, isto é, mediação. A eticidade não se situa ao nível das opiniões subjetivas e caprichos pessoais, que são imediatos e contingentes, mas ao nível das instituições e das leis universais. $\mathrm{O}$ conteúdo do ético é, portanto, necessário e está acima das opiniões contingentes. Por isso, o indivíduo é agora considerado como "membro" (Mitglied). Ao ser objetivada, a vontade de A se nega na vontade de B e assim surge uma vontade mais universal. Se vontade A (tese) e vontade B (antítese) não fossem simultaneamente falsas não seria possível a superação dialética, ou seja, ambas não poderiam estar integradas (superadas e conservadas) numa síntese superior. Na verdade, a vontade A (individual) já é também universal. Minha vontade livre, que se expressa na pretensão de validade de uma máxima, tem que ser mediada pela vontade livre do outro, a fim de poder ser universalizada. $\mathrm{O}$ eu individual se nega para poder efetivar-se como "nós". O imediato tem que ser mediado para que se possa estabelecer um princípio ético universal. Observa-se que a pretensão de validade enunciada pela vontade $\mathrm{A}$ e a enunciada pela vontade $\mathrm{B}$ não podem ser contraditórias e sim, como insiste Cirne Lima, contrárias, uma vez que somente estas podem ser simultaneamente falsas.

$\mathrm{O}$ que se pretende enfatizar na formulação de um princípio ético é que, para tornar possivel a convivência no "nós", as vontades subjetivas imediatas devem ser "superadas" enquanto imediatas: Assim, o ético é um modo de atuar universal porque passou pelo processo de mediação, isto é, negação, processo em que se mostra a falsidade das vontades imediatas dos eus individuais. Só assim poderá ter lugar um conteúdo substancial, ausente, por exemplo, na moral kantiana. Fica claro que o racional não é o imediato, a vontade subjetiva, mas o substancial, no qual o contingente está aufgehoben. Na substância ética a vontade imediata do eu individual foi elevada ao nível da vontade universal porque passou pelo processo dialético de mediação social (leis e instituições) como forma de determinação de seu conteúdo no "nós" família, sociedade civil e Estado.

Tomemos a família como ponto de partida do desdobramento da liberdade nas instituições sociais e observemos como o eu individual torna-se um "nós", ou seja, como o indivíduo passa a ser "membro de" (Mitglied) de uma comunidade, de um conjunto. O conceito de Mitglied expressa bem esta idéia de que o indivíduo já é sempre um universal. Glied (elo) implica já sempre a ligação com outros elos para formar uma grande corrente que só funciona ou só tem utilidade em seu conjunto. A família é o lugar da primeira experiência ou exercício dialético de mediação das vontades. Ela se constitui no movimento triádico do casamento, da propriedade familiar e da educação dos filhos.

O casamento como relação ética imediata tem no amor natural - o sentimento - fundado basicamente no aspecto físico, o ponto de partida subjetivo e totalmente contingente. Além de poder ser motivado por momentos meramente casuais, o 
sentimento não conduz necessariamente ao casamento. Pode eventualmente conduzir a ele. Quer dizer, uma das alternativas possivelmente resultantes do amor natural (sentimento imediato) é o casamento. No entanto, não há instituição do casamento sem o livre consentimento das vontades que estão em jogo. Este é o casamento civil que implica numa relação contratual. Trata-se da dimensão jurídica do casamento. Se o sentimento ou inclinação particular é o ponto de partida subjetivo e, como tal, momento contingente, o livre consentimento das pessoas é o ponto de partida objetivo e necessário; ou seja, o casamento deve realizar o princípio organizador do Direito - a liberdade. Não há casamento sem a manifestação objetiva do reconhecimento das vontades (mesmo que não haja amor nenhum). Dado, no entanto, o caráter contingente destas vontades, o casamento deve superar o sentimento (amor natural) e o aspecto contratual (civil) numa síntese superior que é o amor jurídico-ético. É na negação e superação das inclinações particulares imediatas que o eu individual torna-se nós e a família uma só "pessoa jurídica", ou seja, um nós no qual os eus individuais estão superados e guardados. No consentimento os eus (eu e tu) individuais se reconhecem e negam suas vontades enquanto imediatas e instauram um nível superior de relação ética - o nós. A mediação só é possível se admitirmos que as vontades dos eus contrapostos sejam falsas ou parciais. Se não for assim, não há sintese possivel. No amor jurídico-ético, momento sintético do casamento, estão presentes os momentos anteriores (sentimento, etc.) mas, porque mediados, estão superados e guardados num nível superior. Se tudo fosse contingente não se manteria o casamento como instituição da sociedade e base ética do Estado. As vontades imediatas procurariam tão somente a sua satisfação pessoal e não haveria convivência possivel. A família é, portanto, o lugar do primeiro exercício da vida política. É aí onde se inicia a efetivação da substancialidade ética, que culmina no Estado.

A manifestação externa do "nós" resultante da mediação dos eus individuais no casamento é a propriedade familiar. Hegel a define como realidade externa da família; como potencial capaz de garantir as tarefas próprias da família (cf. Rph. p. 169). A dialética da família, no entanto, se completa na educação dos filhos. Estes representam a sintese enquanto manifestação objetiva do amor dos pais. Indicam, sobretudo, a continuidade do movimento dialético de determinação ou concretização do princípio de liberdade nas instituições sociais e, com isso, a ampliação das relações do eu individual em relação ao nós que se vai universalizando.

No que se refere à propriedade, enquanto familiar, ela já não tem por finalidade satisfazer as carências egoístas dos eus individuais e, sim, as necessidades de um ser "coletivo", um nós, isto é, uma "pessoa substancial". A propriedade é, portanto, um elemento constitutivo da unidade familiar (cf. Weber, 1993, p. 108).

Se a propriedade indica a unidade em algo exterior, os filhos representam a unidade no âmbito espiritual. Daí resulta o papel importante a ser desempenhado pela educação familiar: a formação de uma consciência e vontade coletivas, necessárias para a convivência social. A "exaltação do universal" se constitui na função essencial da educação, na perspectiva da dialética hegeliana (cf. Rph. \& 174). Ora, este processo começa na família, que é uma das bases éticas do Estado.

Ocorre que a familia, dada a maioridade dos filhos, se dissolve e um novo espaço de proteção precisa ser criado. O espaço familiar torna-se insuficiente para 
satisfazer e realizar as necessidades dos eus individuais. Este espaço é preenchido pela sociedade civil e, mais especificamente, pelas corporações que são organizações surgidas a partir da divisão do trabalho e que visam, basicamente, a satisfação das necessidades individuais. Na terminologia hegeliana podemos dizer que na sociedade civil o universal é apenas "fundamento interior" no qual o particular existe como "aparência". Assim, a sociedade civil constitui "o mundo fenomênico do ético" (Rph. \& 181). Ela é o aparecer da verdadeira eticidade ou da unidade substancial. A dissolução da família coloca o individuo numa situação de aparência da universalidade que ele já sempre é e, contudo, pela mediação das vontades, está em constante processo de efetivação.

Compete à sociedade civil constituir a mediação social da liberdade. Dois princípios devem aí ser mediados: a pessoa concreta, enquanto particularidade de interesses, e o contexto social, isto é, cada pessoa particular somente se satisfaz pela mediação da outra, sendo "obrigada a passar pela forma da universalidade" (Rph. \& 182).

É importante observar que o problema da mediação dos interesses particulares com os da coletividade é o fio condutor de todo movimento dialético da mediação social da liberdade. Como, no entanto, há um predomínio dos interesses particulares ou de grupos, sem que haja uma preocupação com o substancial, a sociedade civil se constitui num lugar de conflitos e contradições. O interesse pelo benefício pessoal ou de determinado grupo sobrepõe-se ao interesse da coletividade, não se chegando a elaborar "um sistema verdadeiramente ético das relações inter-humanas" (Dotti, 1983, p. 125). Isto exige um outro fundamento capaz de administrar estes antagonismos, superando-os e guardando-os num nivel superior. Conflitos devem ser superados. Não podemos permanecer nas contradições. Embora elas existam não podemos permanecer nelas.

Considerando a sociedade civil, e nela as corporações, como momento antitético e do predomínio dos interesses privados, cabe ao Estado ser o fundamento último capaz de realizar a substancialidade ética. Hegel define o Estado como sendo "a realidade efetiva da vontade substancial" (Rph,\& 258). Isto significa que, no Estado ideal, pensado, conceitual, a vontade particular foi mediada e elevou-se ao nível de universalidade. Trata-se da "autoconsciência particular elevada à sua universalidade". Isto significa que o indivíduo "é" o Estado e não só faz parte dele. As vontades individuais, através dos diversos niveis de mediação, ficam universais, mas sem deixar de ser elas mesmas, isto é, sem desaparecerem. Trata-se de uma unidade na diversidade. Se o Estado é a organização do poder político que tem em vista fins universais, é em torno destes que os cidadãos devem conciliar suas vontades e chegar a um consenso. Continua, no entanto, aberto um número infinito de alternativas para a livre iniciativa e escolha dos indivíduos.

A concepção de Estado em Hegel, como síntese da eticidade, implica numa distinção fundamental: o Estado Absoluto e os Estados históricos. O primeiro é o ideal, o conceitual, o Estado pensado; os segundos são Estados empiricamente existentes, enquanto concretizações do primeiro. Trata-se da dialética do Ideal e do Real; do que deve ser e do que é. Os Estados históricos são a concretização do Estado Absoluto, embora não sejam sua realização plena. É este antagonismo entre o real (histórico) e o ideal (pensado, conceitual) que move todo processo dialético. 
O que temos em nível de realidade é o não-ser do Estado, ou seja, os Estados históricos são realizações parciais da Idéia do Estado. É importante salientar que assim como o eu individual já sempre é universal, o real (o histórico) também já sempre é o ideal, o conceitual, embora não plenamente realizado. É o movimento das mediações entre os indivíduos, grupos e instituições que torna efetivo o Ideal da racionalidade - a substancialidade ética - representada pelo Estado. É neste sentido que o Estado é o lugar da perfeita integração dos interesses pessoais com os da coletividade. Indica uma espécie de idéia reguladora e ao mesmo tempo constitutiva de todo movimento dialético da vida política.

É importante observar que a dialética da eticidade situa-se na mesma estrutura apresentada por Hegel na Ciência da Lógica. À "lógica do ser" corresponde a família como o imediato e natural; à "lógica da essência", a sociedade civil como a aparência da substancialidade ética, e à "lógica do conceito", o Estado como detentor da eticidade, isto é, o único referencial capaz de garantir toda estrutura da Filosofia do Direito, síntese final de todo processo de determinação do princípio da liberdade. Isto significa dizer que o Estado representa o momento sintético de todo processo de mediação das vontades instaurado no Direito Abstrato.

Nesta dialética da mediação das vontades no Estado, ressurge novamente a grande questão: como conciliar as vontades dos cidadãos enquanto interesses particulares com os interesses universais? Estarão as vontades dos eus individuais superadas e guardadas em proporções iguais em todas as sínteses da realização do processo dialético de determinação da Idéia da liberdade ou serão gradualmente enfraquecidas e por fim eliminadas dentro da vontade substancial do Estado? Como conciliar individualidade com universalidade?

Foi salientado que o eu individual já sempre é universal. Ou seja, o nós é o eu mediado, superado e guardado e, como tal, universalizado. A individualidade pessoal encontra total desenvolvimento de seus interesses particulares na medida em que os converte em "interesse geral" que, por sua vez, é reconhecido como "seu saber e sua vontade". Isto significa que a vontade coletiva ou substancial é a própria vontade dos eus individuais mediada e, por isso, superada e guardada. Para tornar possivel a conciliação dos eus individuais, donde resulta o nós, Hegel fala em mútua restrição de direitos e deveres, no Estado. Os indivíduos têm para com o Estado deveres na medida em que têm direitos e direitos na medida em que têm deveres (cf. Rph, \& 155 e 261). Um escravo, por exemplo, não poderia ter deveres, exatamente porque não tem direitos. Escreve Hegel no \& 261 da Filosofia do Direito: "O Estado, enquanto algo ético, enquanto compenetração do substancial e do particular, implica que minha obrigação frente ao substancial seja ao mesmo tempo a existência de minha liberdade particular, isto é, nele dever e direito estão unidos em uma e mesma relação".

A realização do princípio da liberdade, em todo caso, requer a possibilidade de alternativas dentro do Estado, ou seja, de momentos contingentes que permitem o livre movimento dos eus individuais dentro do universal. Mas e o próprio Estado? No movimento dialético, coloca-se ele como alternativa entre outras possiveis ou é ele a única síntese possível da eticidade e, portanto, uma necessidade indiscutível? Já nos foi dado mostrar que não há outra alternativa fora do Estado como instância capaz de realizar o princípio da liberdade. Nem sequer escolhemos um Estado. Já 
nascemos dentro dele. Uma constituição, por exemplo, já está, de certa forma, feita, uma vez que ela é produto de toda a história de um povo. Ela representa o "espírito de um povo" (Volksgeist), que inclui suas origens, a cultura, seus costumes, etc. O Estado não é um contrato, como queriam Hobbes, Rousseau e outros. Diante da família e da sociedade civil, o Estado é o "fim imanente que tem sua força na unidade de seu fim universal e o interesse particular dos indivíduos, na medida em que estes têm, em relação ao Estado, tanto direitos como deveres" (Rph. \& 261). Como cidadãos da sociedade civil (Estado exterior) os indivíduos são "pessoas privadas" que têm como fim o seu próprio interesse, mas como este está "mediado pelo universal" só pode ser "alcançado na medida em que determinem seu saber, querer e atuar de modo universal, e se transformem em um membro (Glied) da cadeia (Kette) que constitui o conjunto" (Rph. \& 187). A particularidade somente satisfaz seus interesses por meio da universalidade, mas o universal é constituído pelos eus mediados, conservados e superados. Por isso, uma vontade particular, ao se objetivar, se nega para reaparecer na sintese como mais determinada. O Estado aparece como instância necessária (e não contingente), situado acima dos interesses individuais e corporativos, procurando preservar a universalidade na diversidade. O Estado, portanto, dentro da lógica da realização da Idéia da liberdade, é uma necessidade, mas as formas de sua estrutura e organização são contingentes. Há uma margem de alternativas possiveis (é claro, dentro do Estado), com o intuito de realizar a conciliação entre as vontades individuais e a substancialidade ética.

Mas se o Estado é a última instância regradora do exercício da liberdade dos cidadãos, quem avalia e julga o seu desempenho na tentativa de realizar seu objetivo? A resposta de Hegel é clara: Os Estados históricos estão constantemente submetidos ao tribunal da história. É por isso que sua Filosofia do Direito reporta à Filosofia da História.

\section{Bibliografia}

HEGEL, G. W. F. Phänomenologie des Geistes. Frankfurt am Main: Suhrkamp, 1986.

. Grundlinien der Philosophie des Rechts. Frankfurt am Main: Suhrkamp, 1986.

Wissenschaft der Logik I und II. Frankfurt am Main: Suhrkamp, 1986.

BOBBIO, N. Estudos sobre Hegel. Direito, Sociedade Civil, Estado. São Paulo: Brasiliense, 1991.

WEBER, Thadeu. Hegel: Liberdade, Estado e História. Petrópolis: Vozes, 1993.

DOTTI, J. E. Dialéctica y Derecho. Buenos Aires: Hachette, 1983.

KANT, I. Crítica da Razão Prática. Lisboa: Edições 70, 1986.

CIRNE LIMA, C. R. "Dialética e Evolução". Porto Alegre: Veritas, v. 40, n² 160, 1995.

POPPER, S. K. "O que é Dialética?" In: Conjecturas e Refutações. Brasilia: UnB, 1972.

GADAMER, H. G. La Dialéctica de Hegel. Cinco ensayos hermenéuticos. Madrid: Ed. Cátedra, 1981.

FLOREZ, Ramiro. La Dialéctica de la Historia en Hegel. Madrid: Gredos, 1983. 